\title{
Low interim influenza vaccine effectiveness, Australia, 1 May to 24 September 2017
}

Sheena G Sullivan 1,2,3, Monique B Chilver ${ }^{3}$, Kylie S Carville ${ }^{4}$, Yi-Mo Deng ${ }^{1}$, Kristina A Grant ${ }^{4}$, Geoff Higgins ${ }^{5}$, Naomi Komadina ${ }^{1}$, Vivian KY Leung ${ }^{1}$, Cara A Minney-Smith ${ }^{6}$, Don Teng ${ }^{7}$, Thomas Tran ${ }^{4}$, Nigel Stocks 3 , James E Fielding ${ }^{2,4}$

1. WHO Collaborating Centre for Reference and Research on Influenza, Melbourne, Australia

2. School of Global and Population Health, University of Melbourne, Australia

3. Discipline of General Practice, University of Adelaide, Australia

4. Victorian Infectious Diseases Reference Laboratory, Melbourne, Australia

5. SA Pathology, Adelaide, Australia

6. PathWest Laboratory Medicine WA, Perth, Australia

7. School of Biomedical Sciences, Monash University, Melbourne, Australia

Correspondence: Sheena G Sullivan (sheena.sullivan@influenzacentre.org)

Citation style for this article:

Sullivan Sheena G, Chilver Monique B, Carville Kylie S, Deng Yi-Mo, Grant Kristina A, Higgins Geoff, Komadina Naomi, Leung Vivian KY, Minney-Smith Cara A, Teng Don, Tran Thomas, Stocks Nigel, Fielding James E. Low interim influenza vaccine effectiveness, Australia, 1 May to 24 September 2017 . Euro Surveill. 2017;22(43):pii=17-00707. https://doi.org/10.2807/1560-7917.ES.2017.22.43.17-00707

In 2017, influenza seasonal activity was high in the southern hemisphere. We present interim influenza vaccine effectiveness (VE) estimates from Australia. Adjusted VE was low overall at 33\% (95\% confidence interval ( $\mathrm{Cl}): 17$ to 46$), 50 \%(95 \% \mathrm{Cl}: 8$ to 74$)$ for $\mathrm{A}\left(\mathrm{H}_{1}\right)$ pdmo9, $10 \%$ (95\% Cl: -16 to 31) for $\mathrm{A}\left(\mathrm{H}_{3}\right)$ and $57 \%(95 \%$ $\mathrm{Cl}: 41$ to 69) for influenza $\mathrm{B}$. For $\mathrm{A}\left(\mathrm{H}_{3}\right)$, VE was poorer for those vaccinated in the current and prior seasons.

The ongoing Australian 2017 influenza season was so far characterised by record-high laboratory-confirmed influenza notifications [1], high consultation rates, high hospitalisation and mortality rates, particularly in New South Wales [2], large numbers of institutional outbreaks [2] and media attention. The southern hemisphere influenza vaccine used in Australia for this season was a quadrivalent formulation comprised of an A/Michigan/45/2015 ( $\left.\mathrm{H}_{1} \mathrm{~N}_{1}\right)$ pdmog-like virus, an $\mathrm{A} /$ Hong Kong/4801/2014 ( $\left.\mathrm{H}_{3} \mathrm{~N}_{2}\right)$-like virus, a B/ Brisbane/6o/2008-like virus (of the $\mathrm{B} /$ Victoria/2/87 lineage) and a B/Phuket/3073/2013-like virus (of the $B /$ Yamagata/16/88 lineage) $[3,4]$. This same vaccine composition is being used in the upcoming northern hemisphere for the $2017 / 18$ influenza season [5]. Here we report interim influenza vaccine effectiveness estimates for 2017 in Australia, using sentinel surveillance data.

\section{Data collection}

The Australian Sentinel Practices Research Network (ASPREN) and the Victorian Sentinel Practice Influenza Network (VicSPIN) constitute Australia's two sentinel influenza general practice (GP) networks. VicSPIN operates in the state of Victoria, while ASPREN operates nationally. Both surveillance systems use similar data collection methods $[6,7]$, with the key difference that the VicSPIN surveillance period is limited to weeks 18 to 43 (1 May 1- 29 October), timed to start roughly 2 weeks after vaccination campaigns in midApril. Briefly, sentinel GPs submit weekly reports of the number of patients seen with influenza-like illness (ILI), defined as fever/history of fever, cough and fatigue, and the total number of patients. Nose/ throat swabs are collected from a subset of patients with demographic data, date of ILI onset, vaccination status (self-reported or medical record) and indications for vaccination, such as belonging to an influenza risk group. Swabs are tested by RT-PCR and positive samples are referred to the World Health Organization (WHO) Collaborating Centre for Reference and Research on Influenza in Melbourne, for antigenic characterisation by haemagglutination inhibition assay ( $\mathrm{HAl}$ ) [8] or focus reduction assay (FRA) [9] and genetic sequencing, as described previously [6]. All data were managed and analysed using $R$ version 3.4.1.

\section{Influenza-like illness activity}

ILI data from ASPREN for 2017 and 2012 to 2016 (averaged) are plotted in Figure $1 \mathrm{~A}$ and indicate consultation rates were higher in 2017 than in the previous 5 years. For the study period from 1 May 2017 to 24 September 2017, i.e. weeks $18-38$, the 262 ASPREN GPs and 88 VicSPIN GPs conducted 493,961 consultations, of which $5,678(1.1 \%)$ met the ILI case definition and swabs were collected from 2,465 (43\%) of them. Influenza cases were detected in every week of the study period and peaked in week 34 (21-27 August, $n=235)$. Percentage of positive samples peaked in week 32 (7-13 August) with $58 \%$. 


\section{FIGURE 1}

Sentinel general practice (GP) surveillance dataa, (A) ILI consultation rates, (B) laboratory detections of influenza patients by week and type/subtype, Australia, 2 January-24 September 2017

A.

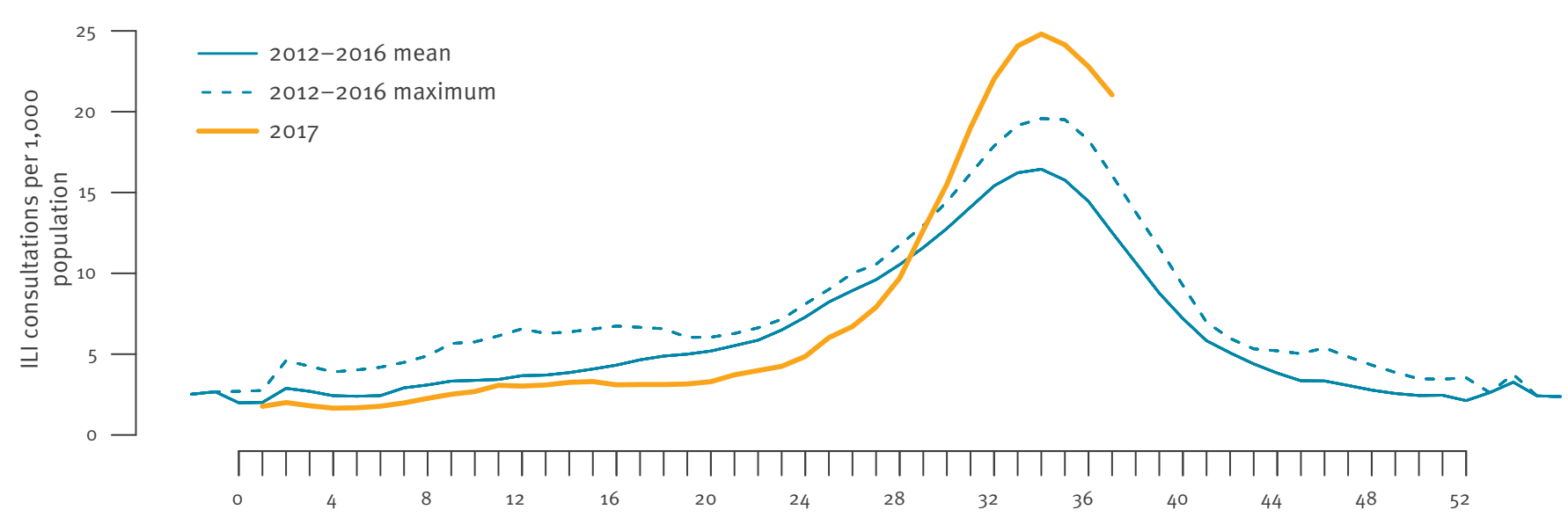

B.

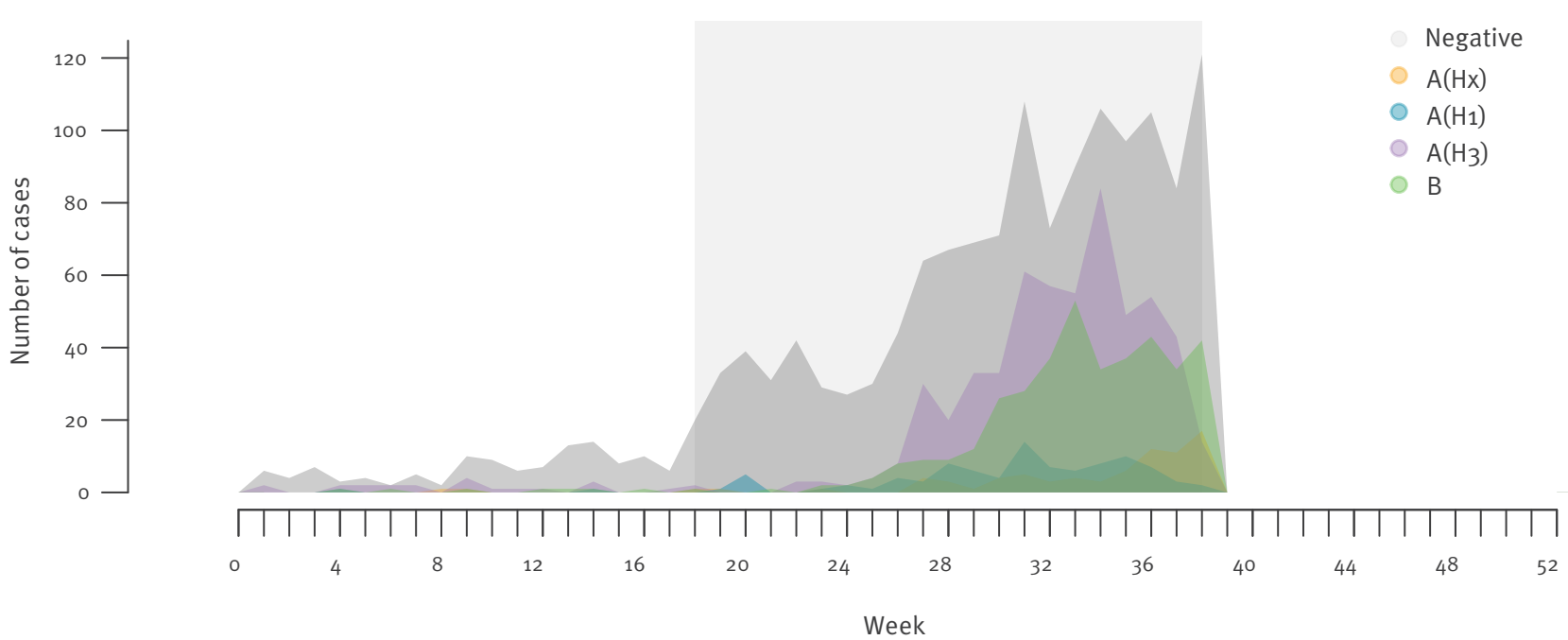

ILI: influenza-like-illness.

a Data from the Australian Sentinel Practices Research Network. Victorian Sentinel Practice Influenza Network data (not shown) demonstrated a similar pattern.

In panel $A$ the mean and maximum are calculated by first aligning the peaks for each season, then calculating the weekly mean and maximum consultation rate, as described in [22].

In panel B the shaded rectangular area shows the weeks for which data were included in the vaccine effectiveness analyses, 1 May 2017 to 24 September 2017.

\section{Virological characteristics}

Virological analyses and vaccine effectiveness estimation were restricted to the period 1 May to 24 September (weeks 18-38). During this period, 2,456 patients were swabbed, but samples from 116 patients were excluded because of missing information on vaccination status, and one with missing influenza status. Among the remaining 2,339 patients, working-age adults comprised the majority $(n=1,604,69 \%), 440$ (19\%) were aged $<15$ years and 297 (13\%) were aged $\geq 65$ years. Around $37 \%(477 / 1,279)$ of test-negative patients were vaccinated in 2017 .

Eighty-eight patients tested positive for $A\left(\mathrm{H}_{1}\right)$ pdmo9, 522 were $A\left(H_{3}\right), 75$ were not yet subtyped, 11 were $B /$ Victoria, 259 were B/Yamagata and 105 were influenza 


\section{FIGURE 2}

Phylogenetic tree for the haemagglutinin gene of influenza $\mathrm{A}(\mathrm{H} 3)$ viruses

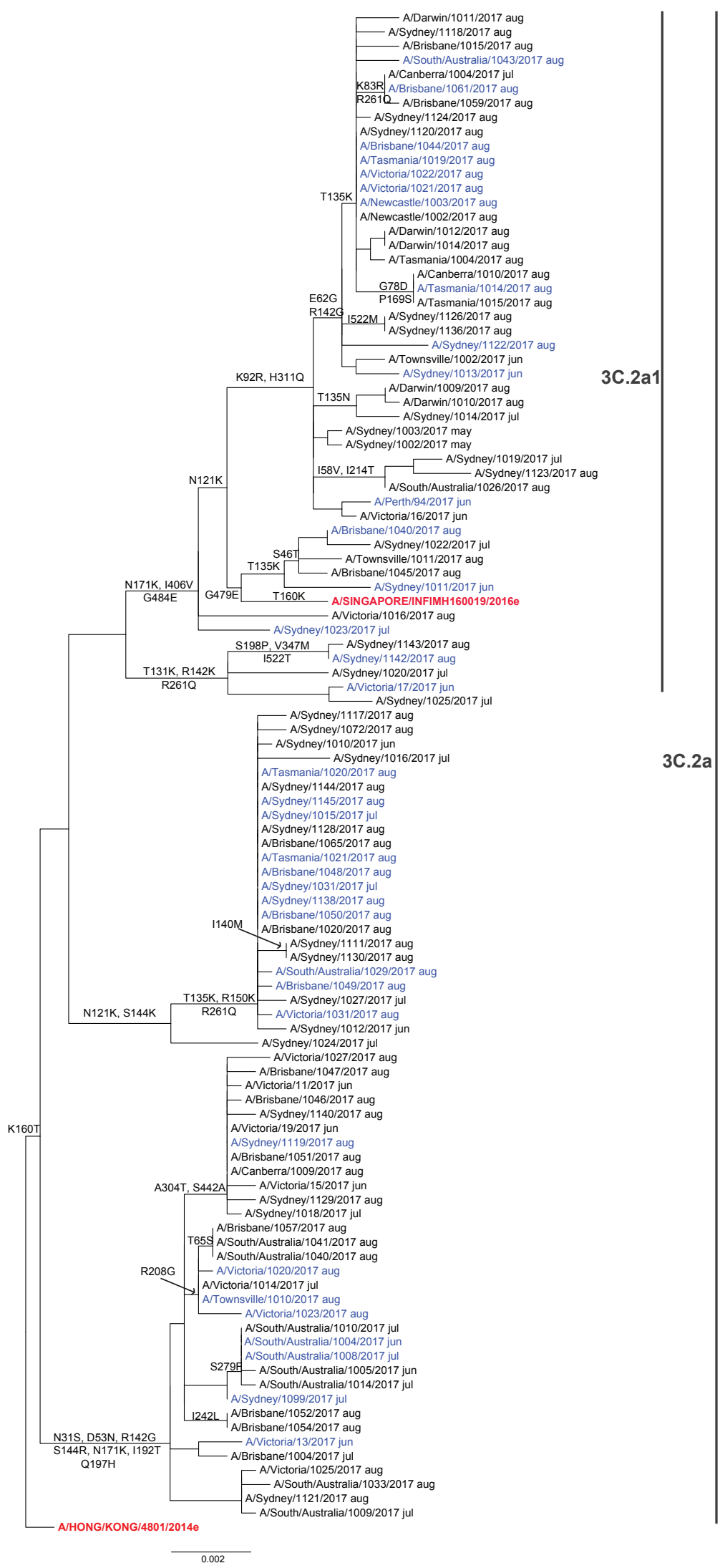

The phylogenetic tree was created using GENEiOUS, (Biomatters Limited.), Randomized Axelerated Maximum Likelihood (RAxML) Version 8, and Phylogenetic Analysis by Maximum Likelihood (PAML). Blue colouring indicates the virus came from a vaccinated patient. Red colouring indicates vaccine reference viruses. Not all viruses analysed are shown. There were $128(62 \%) 3 C .2$ a viruses, among which there were several variants when compared with the vaccine strain, A/Hong Kong/4801/2014, all but three of which included the gain of a potential glycosylation site at position $160(\mathrm{~K} 160 \mathrm{~T}(+))$, which distinguishes these viruses from the vaccine strain. Additional substitutions included 59 viruses characterised by substitutions at N31S, D53N,R142G, S144R,N171K, I192T, 45 by N121K, S144K, and 15 by T131K, R142K, R261Q. Seventy-

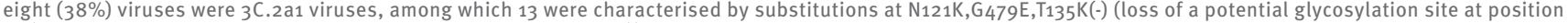
135) and 61 by $\mathrm{K} 92 \mathrm{R}, \mathrm{N} 121 \mathrm{~K}, \mathrm{H} 311 \mathrm{Q}$ including 34 that also had $\mathrm{T} 135 \mathrm{~K}(-)$. 
TABLE 1

Antigenic analysis of virus isolates collected during the influenza season, Australia, 1 May-24 September 2017

\begin{tabular}{|c|c|c|c|c|c|c|}
\hline \multirow[t]{2}{*}{ Influenza strain } & \multirow[t]{2}{*}{ Total viruses attempted ${ }^{a}$} & \multirow[t]{2}{*}{ Type of assay } & \multicolumn{2}{|c|}{$\begin{array}{l}\text { Cell-propagated } \\
\text { reference strain }\end{array}$} & \multicolumn{2}{|c|}{$\begin{array}{l}\text { Egg-propagated } \\
\text { reference strain }\end{array}$} \\
\hline & & & Like & Low-reacting & Like & Low-reacting \\
\hline $\mathrm{A}(\mathrm{H} 1) \mathrm{pdmog} \mathrm{A} /$ Michigan/45/2015 & 55 & \multicolumn{5}{|c|}{ NA } \\
\hline Positive & 48 & HAI & 46 & 0 & 46 & o \\
\hline Insufficient HA Titre for HAI & 1 & \multicolumn{5}{|c|}{ NA } \\
\hline $\mathrm{A}\left(\mathrm{H}_{3}\right) \mathrm{A} /$ Hong Kong/4801/2014 & 265 & \multicolumn{5}{|c|}{ NA } \\
\hline \multirow{2}{*}{ Positive } & \multirow{2}{*}{90} & $\mathrm{HAl}$ & 60 & 7 & 45 & 22 \\
\hline & & FRA & 31 & 0 & 28 & 3 \\
\hline Insufficient HA Titre for HAI & 98 & FRA & 44 & 0 & 32 & 12 \\
\hline $\mathrm{B} /$ Victoria $\mathrm{B} /$ Brisbane/60/2008 & 7 & \multicolumn{5}{|c|}{ NA } \\
\hline Positive & 6 & HAI & 3 & 1 & 0 & 4 \\
\hline B/Yamagata B/Phuket/3073/2013 & 148 & \multicolumn{5}{|c|}{ NA } \\
\hline Positive & 90 & $\mathrm{HAl}$ & 52 & 0 & 50 & 2 \\
\hline
\end{tabular}

FRA: focus reduction assay; HAI: haemagglutination inhibition assay. HA: haemagglutinin; NA: not applicable.

${ }^{a}$ Virus isolation was not attempted for all viruses and not all isolates were analysed by HAI or FRA; FRA was only attempted for $A\left(\mathrm{H}_{3}\right)$ viruses.

${ }^{b}$ Results for post-infection ferret antisera raised to egg-propagated and cell-propagated reference viruses are presented because the eggpropagated reference viruses more closely resemble the vaccine strain, while cell-propagated reference viruses more closely resemble the original virus from which the vaccine strain was derived.

$B$, but the lineage was not yet determined (Figure $1 \mathrm{~B}$ ). Virus isolation was attempted for samples with a cycle threshold value of 30 or less (Table 1). HAl testing indicated that isolates were generally antigenically similar to their respective vaccine strains. Thirty-seven percent $(n=98)$ of $A\left(\mathrm{H}_{3}\right)$ viruses yielded insufficient haemagglutinin titres for testing by $\mathrm{HAl}$ and were instead assessed by FRA. In HAI and FRA, 10\% (7/67) and ०\% (o/75) of $A\left(\mathrm{H}_{3}\right)$ viruses, respectively, were low reacting to post-infection ferret antisera raised to cell-propagated A/Hong Kong/4801/2014-like viruses. However, these proportions increased to $33 \%(22 / 67)$ and $20 \%$ (15/75), respectively, when tested against egg-propagated reference virus.

Sequences for the haemagglutinin gene were available for a subset of $\mathrm{A}\left(\mathrm{H}_{3}\right)$ viruses (Figure 2). Examination of the phylogenetic tree identified considerable diversity with a number of viruses exhibiting amino acid substitutions in key glycosylation and antigenic sites but no specific clustering of vaccine failures. GISAID accession numbers for these viruses were 271246,271303 , 275219, 275220, 275225, 275226, 275227, 275228, 275246, 275247, 275248, 275278, 275280, 277305, $277315,277557$.

\section{Vaccines effectiveness estimates}

Vaccine effectiveness (VE) was estimated following a case-control test-negative design, where VE is estimated from the odds ratio (OR) comparing the odds of vaccination among test-positive and test-negative patients. The limitations of this design have been discussed at length $[10,11]$. Estimates were adjusted for week of specimen collection (cubic spline with 4 knots), and age group (spline with knots at 5, 15, 35, 65,75 years).

VE estimates are shown in Table 2. Overall VE was 33\% ( $95 \% \mathrm{Cl}: 17$ to 46 ). This estimate appeared to be skewed by the very low estimate for $\mathrm{A}\left(\mathrm{H}_{3}\right)$, which was $10 \%$ (95\% $\mathrm{Cl}:-16$ to 31 ), whereas estimates were higher for A(H1)pdmog (VE: $50 \%$; $95 \% \mathrm{Cl}: 8$ to 74 ) and B (VE: $57 \%$; $95 \% \mathrm{Cl}: 41$ to 69$)$. VE for $\mathrm{A}\left(\mathrm{H}_{3}\right) 3 \mathrm{C} .2 \mathrm{a}$ viruses was $5 \%$ ( $95 \% \mathrm{Cl}:-51$ to 40 ), while the estimate for $3 \mathrm{C} .2 \mathrm{a} 1$ was $19 \%$ ( $95 \% \mathrm{Cl}:-42$ to 55 ). For patients vaccinated in the 2016 season, VE for $A\left(\mathrm{H}_{3}\right)$ was $3-4 \%$ regardless of whether they were also vaccinated in 2017 . In contrast, the highest VE point estimates for influenza B were observed among those vaccinated in both 2016 and 2017.

\section{Discussion}

Our interim analysis suggests moderate VE against influenza $A\left(\mathrm{H}_{1}\right)$ pdmog and influenza $B$. However, VE was low against influenza $A\left(\mathrm{H}_{3}\right)$. The antigenic data reflect ongoing issues with $\mathrm{A}\left(\mathrm{H}_{3}\right)$ candidate vaccine viruses which, when propagated in eggs, rapidly acquire adaptive changes in the haemagglutinin which alter antigenicity. Cell-based vaccines, which are less affected by this, are only licensed in the United States, were not available in Australia in 2017 and will also not be available for the upcoming European season. 
TABLE 2

Interim sample characteristics and vaccine effectiveness estimates, Australia, 1 May 2017-24 September 2017

\begin{tabular}{|c|c|c|c|c|c|c|c|c|c|c|}
\hline \multirow{2}{*}{ Type/subtype } & \multirow{3}{*}{$\begin{array}{l}\text { Age group } \\
\text { All ages }\end{array}$} & \multicolumn{4}{|c|}{ Cases } & \multicolumn{4}{|c|}{ Controls } & \multirow{3}{*}{ 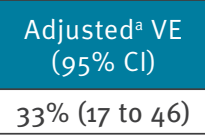 } \\
\hline & & \multicolumn{2}{|c|}{ Unvaccinated } & \multicolumn{2}{|c|}{ Vaccinated } & \multicolumn{2}{|c|}{ Unvaccinated } & \multicolumn{2}{|c|}{ Vaccinated } & \\
\hline \multirow{4}{*}{$A$ or $B$} & & 772 & $73 \%$ & 288 & $27 \%$ & 802 & $63 \%$ & 477 & $37 \%$ & \\
\hline & Children $<15 y$ & 235 & $94 \%$ & 14 & $6 \%$ & 179 & $94 \%$ & 12 & $6 \%$ & $16 \%(-95$ to 63$)$ \\
\hline & Adults $15-64 \mathrm{y}$ & 512 & $74 \%$ & 181 & $26 \%$ & 587 & $65 \%$ & 322 & $35 \%$ & $39 \%$ (24 to 51$)$ \\
\hline & Adults $\geq 65 y$ & 25 & $21 \%$ & 93 & $79 \%$ & 36 & $20 \%$ & 143 & $80 \%$ & $-3 \%(-92$ to 44$)$ \\
\hline \multirow{4}{*}{$\mathrm{A}\left(\mathrm{H}_{1}\right) \mathrm{pdmog}$} & All ages & 74 & $84 \%$ & 14 & $16 \%$ & 802 & $63 \%$ & 477 & $37 \%$ & $50 \%(8$ to 74$)$ \\
\hline & Children $<15 y$ & 33 & $97 \%$ & 1 & $3 \%$ & 179 & $94 \%$ & 12 & $6 \%$ & $\mathrm{NE}$ \\
\hline & Adults $15-64 \mathrm{y}$ & 40 & $78 \%$ & 11 & $22 \%$ & 587 & $65 \%$ & 322 & $35 \%$ & $49 \%(2$ to 76$)$ \\
\hline & Adults $\geq 65 y$ & 1 & $33 \%$ & 2 & $67 \%$ & 36 & $20 \%$ & 143 & $80 \%$ & $\mathrm{NE}$ \\
\hline \multirow{4}{*}{$A\left(H_{3}\right)$} & All ages & 347 & $66 \%$ & 175 & $34 \%$ & 802 & $63 \%$ & 477 & $37 \%$ & $10 \%(-16$ to 31$)$ \\
\hline & Children $<15 y$ & 100 & $94 \%$ & 6 & $6 \%$ & 179 & $94 \%$ & 12 & $6 \%$ & $17 \%(-132$ to 33$)$ \\
\hline & Adults $15-64 y$ & 233 & $68 \%$ & 110 & $32 \%$ & 587 & $65 \%$ & 322 & $35 \%$ & $16 \%(-11$ to 36$)$ \\
\hline & Adults $\geq 65 y$ & 14 & $19 \%$ & 59 & $81 \%$ & 36 & $20 \%$ & 143 & $80 \%$ & $\begin{array}{c}-20 \%(-160 \text { to } \\
42) \\
\end{array}$ \\
\hline \multirow{4}{*}{$\begin{array}{l}\mathrm{A}\left(\mathrm{H}_{3}\right) \text { Clade } \\
3 \mathrm{C} .2 \mathrm{a}\end{array}$} & All ages & 88 & $69 \%$ & 40 & $31 \%$ & 802 & $63 \%$ & 477 & $37 \%$ & $5 \%(-51$ to 40$)$ \\
\hline & Children $<15 y$ & 31 & $94 \%$ & 2 & $6 \%$ & 179 & $94 \%$ & 12 & $6 \%$ & $\mathrm{NE}$ \\
\hline & Adults $15-64 \mathrm{y}$ & 56 & $68 \%$ & 26 & $32 \%$ & 587 & $65 \%$ & 322 & $35 \%$ & $14 \%(-40$ to 49$)$ \\
\hline & Adults $\geq 65 y$ & 1 & $8 \%$ & 12 & $92 \%$ & 36 & $20 \%$ & 143 & $80 \%$ & NE \\
\hline \multirow{4}{*}{$\begin{array}{l}\mathrm{A}\left(\mathrm{H}_{3}\right) \text { Clade } \\
{ }_{3 \mathrm{C} .2 \mathrm{a} 1}\end{array}$} & All ages & 52 & $67 \%$ & 26 & $33 \%$ & 802 & $63 \%$ & 477 & $37 \%$ & $19 \%(-42$ to 55$)$ \\
\hline & Children <15y & 14 & $93 \%$ & 1 & $7 \%$ & 179 & $94 \%$ & 12 & $6 \%$ & $\mathrm{NE}$ \\
\hline & Adults $15-64 \mathrm{y}$ & 37 & $76 \%$ & 12 & $24 \%$ & 587 & $65 \%$ & 322 & $35 \%$ & $40 \%(-14$ to 71$)$ \\
\hline & Adults $\geq 65 y$ & 1 & $7 \%$ & 13 & $93 \%$ & 36 & $20 \%$ & 143 & $80 \%$ & $\mathrm{NE}$ \\
\hline \multirow{4}{*}{ B } & All ages & 306 & $82 \%$ & 69 & $18 \%$ & 802 & $63 \%$ & 477 & $37 \%$ & $57 \%$ (41 to 69$)$ \\
\hline & Children <15y & 91 & $96 \%$ & 4 & $4 \%$ & 179 & $94 \%$ & 12 & $6 \%$ & $\mathrm{NE}$ \\
\hline & Adults $15-64 \mathrm{y}$ & 208 & $82 \%$ & 45 & $18 \%$ & 587 & $65 \%$ & 322 & $35 \%$ & $63 \%(48$ to 74$)$ \\
\hline & Adults $\geq 65 y$ & 7 & $26 \%$ & 20 & $74 \%$ & 36 & $20 \%$ & 143 & $80 \%$ & $10 \%(-156$ to 65$)$ \\
\hline \multirow{4}{*}{ B/Victoria } & All ages & 11 & $100 \%$ & 0 & $0 \%$ & 802 & $63 \%$ & 477 & $37 \%$ & $\mathrm{NE}$ \\
\hline & Children <15y & 4 & $100 \%$ & 0 & $0 \%$ & 179 & $94 \%$ & 12 & $6 \%$ & $\mathrm{NE}$ \\
\hline & Adults $15-64 \mathrm{y}$ & 7 & $100 \%$ & 0 & $0 \%$ & 587 & $65 \%$ & 322 & $35 \%$ & $\mathrm{NE}$ \\
\hline & Adults $\geq 65 y$ & 0 & NA & 0 & NA & 36 & $20 \%$ & 143 & $80 \%$ & $\mathrm{NE}$ \\
\hline \multirow{4}{*}{ B/Yamagata } & All ages & 206 & $80 \%$ & 53 & $20 \%$ & 802 & $63 \%$ & 477 & $37 \%$ & $45 \%(22$ to 62$)$ \\
\hline & Children <15y & 71 & $96 \%$ & 3 & $4 \%$ & 179 & $94 \%$ & 12 & $6 \%$ & $\mathrm{NE}$ \\
\hline & Adults $15-64 \mathrm{y}$ & 130 & $77 \%$ & 38 & $23 \%$ & 587 & $65 \%$ & 322 & $35 \%$ & $49 \%(26$ to 66$)$ \\
\hline & Adults $\geq 65 y$ & 5 & $29 \%$ & 12 & $71 \%$ & 36 & $20 \%$ & 143 & $80 \%$ & $27 \%(-162$ to 77$)$ \\
\hline \multicolumn{11}{|c|}{ Repeated vaccination - Influenza A(H1)pdmo9 } \\
\hline \multicolumn{2}{|l|}{ Neither season } & 63 & $73 \%$ & NA & NA & 647 & $52 \%$ & NA & NA & Ref \\
\hline Both 2016 and & & NA & NA & 13 & $15 \%$ & NA & NA & 395 & $32 \%$ & $\mathrm{NE}$ \\
\hline 2017 only & & NA & NA & 1 & $1 \%$ & NA & NA & 59 & $5 \%$ & $\mathrm{NE}$ \\
\hline 2016 only & & NA & NA & 9 & $10 \%$ & NA & NA & 132 & $11 \%$ & $\mathrm{NE}$ \\
\hline Repeated vacci & enza $A\left(H_{3}\right)$ & & & & & & & & & \\
\hline Neither season & & 294 & $17 \%$ & NA & NA & 647 & $52 \%$ & NA & NA & Ref \\
\hline Both 2016 and & & NA & NA & 155 & $30 \%$ & NA & NA & 395 & $32 \%$ & $3 \%(-29$ to 27$)$ \\
\hline 2017 only & & NA & NA & 14 & $3 \%$ & NA & NA & 59 & $5 \%$ & $43 \%(-1$ to 71$)$ \\
\hline 2016 only & & NA & NA & 47 & $9 \%$ & NA & NA & 132 & $11 \%$ & $4 \%(-40$ to 36$)$ \\
\hline Repeated vacci & enza B & & & & & & & & & \\
\hline Neither season & & 262 & $72 \%$ & NA & NA & 647 & $52 \%$ & $\mathrm{NA}$ & NA & Ref \\
\hline Both 2016 and & & NA & NA & 57 & $16 \%$ & NA & NA & 395 & $32 \%$ & $59 \%(42$ to 72$)$ \\
\hline 2017 only & & NA & NA & 11 & $3 \%$ & NA & NA & 59 & $5 \%$ & $50 \%(4$ to 76$)$ \\
\hline 2016 only & & NA & NA & 36 & $10 \%$ & NA & NA & 132 & $11 \%$ & $22 \%(-18$ to 47$)$ \\
\hline
\end{tabular}

$\mathrm{CI}$ : confidence interval; NA: not applicable; NE: not estimated (because cell counts are fewer than five); Ref: reference category VE: vaccine effectiveness; $y$ : years.

Numbers are shown for all groups regardless of whether VE estimation was attempted. VE was only estimated where cell counts were at least five. Although presented, estimates for children and those aged $\geq 65$ years typically have wide Cls and should be interpreted with caution. Note that the same control group is used for all comparisons within an age group.

${ }^{a}$ All estimates adjusted for calendar time (cubic spline function with 4 knots). Estimates for all ages were also adjusted for age (cubic spline with knots at $5,15,35,65,75)$. 
The significant genetic diversity of circulating viruses, many of which exhibit amino acid substitutions in key antigenic and glycosylation sites, also makes it difficult to select candidate vaccine viruses with high coverage.

This was the second season for which the A/Hong Kong/4801/2015-containing vaccine was used in Australia [3,12], and campaigns currently underway in the northern hemisphere are also using it for a second time $[5,13]$. During the 2016/17 northern hemisphere season interim VE estimates ranged from $15 \%(95 \% \mathrm{Cl}$ : -11 to 35 ) to $43 \%$ (95\%Cl: 29 to 54$)$ [14-17]. It is unclear whether sequential vaccination will result in lower estimates for $2017 / 18$, but our VE estimates were particularly low for people who received vaccine in 2016 and for older adults, $76 \%$ of whom were sequentially vaccinated. This finding is consistent with a modelling study which predicts low VE for sequentially vaccinated persons when the vaccine composition is identical, but the antigenic distance between the vaccine and circulating strains is high [18]. However, confounding due to prior infection status and negative interference from pre-2016 vaccines could not be controlled for in our analysis, and may have introduced bias.

In contrast to $A\left(\mathrm{H}_{3}\right)$, VE estimates for influenza $B$ were moderate and the combined effects of vaccination in 2016 and 2017 did not blunt effectiveness for influenza $B$, even though the composition remained the same. Similarly, VE for the few $\mathrm{A}\left(\mathrm{H}_{1}\right)$ pdmog cases recruited was moderate, although low for Australia at 50\% ( $95 \% \mathrm{Cl}: 8$ to 74 ), where VEs have ranged from $54 \%$ to $79 \%$ in the past $[6,7]$. This was the one component of the 2017 vaccine that was updated since 2016 , from A/ California/7/2009 to A/Michigan/45/2015.

This study provides interim estimates of the 2017 southern hemisphere influenza vaccine in the outpatient setting and may not apply to inpatient settings or severe illness. Interim estimates can reliably predict final season estimates [19], particularly when made after the peak [20], as is the case here. Should the circulating $\mathrm{A}\left(\mathrm{H}_{3}\right)$ influenza viruses predominate in the 2017/18 northern hemisphere influenza season [21], our results suggest that the vaccine may confer limited protection. Health authorities should consider other influenza prevention measures, including antivirals and health promotion messaging, in the event of a severe season and low VE against $A\left(\mathrm{H}_{3}\right)$.

\section{Acknowledgements}

We thank the general practitioners, nurse practitioners, and practice staff that participated and contributed to ASPREN and VicSPIN in 2017. We also thank laboratory staff members from the following laboratories who undertook influenza testing and virus characterisation: SA Pathology, Adelaide, South Australia; PathWest Laboratory Medicine, Perth, Western Australia; the Victorian Infectious Diseases Reference Laboratory, Melbourne, Victoria; and the WHO Collaborating Centre for Reference and Research on Influenza, Melbourne, Victoria. ASPREN and the WHO Collaborating Centre for Reference and Research on Influenza are supported by the Australian Government Department of Health (the Department). The opinions expressed in this paper are those of the authors, and do not necessarily represent the views of the Department. VicSPIN is funded by the Victorian Government Department of Health and Human Services. DT is supported by contract HHSN272201400006C from the National Institute of Allergy and Infectious Disease, National Institutes of Health, Department of Health and Human Services, USA.

\section{Conflict of interest}

None declared.

Authors' contributions

Project leads: SGS (WHOCC), MBC (ASPREN), JEF (VicSPIN); Virus testing: GH,YMD (ASPREN), CMS (ASPREN for Western Australia), TT (VicSPIN); Virus sequencing: YMD; Data analysis: SGS (epidemiological); NK, DT (phylogenetic); Preparation of first draft: SGS, MBC, JEF. All co-authors contributed epidemiological and/or virological data, contributed to the design and interpretation of the results, reviewed the early draft and approved the final version.

\section{References}

1. Australian Government. Department of Health. Australian Influenza Surveillance Report No 10 - week ending 29 September 2017. Canberra: Department of Health; 2017. Available from: http://www.health.gov.au/internet/main/ publishing.nsf/Content/ozflu-surveil-no10-17.htm

2. NSW Government. Health. Influenza Surveillance Report, Week 39: 25 September to 1 October 2017. North Sydney: NSW Government. [Accessed 25 Oct 2017]. Available from: http://www.health.nsw.gov.au/Infectious/Influenza/ Publications/2017/weekending-01102017.pdf

3. World Health Organization (WHO). Recommended composition of influenza virus vaccines for use in the 2017 southern hemisphere influenza season. Geneva: WHO; 29 Sep 2016. Available from: http://www.who.int/influenza/vaccines/virus/ recommendations/2017 south/en/

4. Australian Government. Department of Health. Therapeutic Goods Administration. 2017 seasonal influenza vaccines. Symonston: Therapeutic Goods Administration; 6 Mar 2017. Available from: https://www.tga.gov.au/ media-release/2017-seasonal-influenza-vaccines

5. World Health Organization (WHO). Recommended composition of influenza virus vaccines for use in the 2017-2018 northern hemisphere influenza season. Geneva: WHO; 2017. Available from: http://www.who.int/influenza/vaccines/virus/ recommendations/2017 18 north/en/

6. Fielding JE, Levy A, Chilver MB, Deng YM, Regan AK, Grant KA et al. Effectiveness of seasonal influenza vaccine in Australia, 2015: An epidemiological, antigenic and phylogenetic assessment. Vaccine. 2016;34(41):4905-12. https://doi. org/10.1016/j.vaccine.2016.08.067 PMID: 27577556

7. Sullivan SG, Carville KS, Chilver M, Fielding JE, Grant KA, Kelly $\mathrm{H}$, et al. Pooled influenza vaccine effectiveness estimates for Australia, 2012-2014. Epidemiol Infect. 2016;144(11):2317-28. https://doi.org/10.1017/S0950268816000819 PMID: 27125368

8. Hobson D, Curry RL, Beare AS, Ward-Gardner A. The role of serum haemagglutination-inhibiting antibody in protection against challenge infection with influenza $A 2$ and $B$ viruses. J Hyg (Lond). 1972;70(4):767-77. https://doi.org/10.1017/ So022172400022610 PMID: 4509641

9. Lin Y, Gu Y, McCauley JW. Optimization of a Quantitative Micro-neutralization Assay. I Vis Exp. 2016; (118). https://doi. org/10.3791/54897 PMID: 28060291

10. Foppa IM, Haber M, Ferdinands JM, Shay DK. The case test-negative design for studies of the effectiveness of influenza vaccine. Vaccine. 2013;31(30):3104-9. https://doi. org/10.1016/j.vaccine.2013.04.026 PMID: 23624093

11. Sullivan SG, Tchetgen Tchetgen EJ, Cowling BJ. Theoretical basis of the test-negative study design for assessment of influenza vaccine effectiveness. Am J Epidemiol. 2016;184(5):345-53. https://doi.org/10.1093/aje/kwwo64 PMID: 27587721 
12. World Health Organization (WHO). Recommended composition of influenza virus vaccines for use in the 2016 southern hemisphere influenza season. Geneva: WHO; 24 Sep 2015. Available from: http://www.who.int/influenza/vaccines/virus/ recommendations/2016_south/en/

13. World Health Organization (WHO). Recommended composition of influenza virus vaccines for use in the 2016-2017 northern hemisphere influenza season. Geneva: WHO; 25 Feb 2016.

Available from: http://www.who.int/influenza/vaccines/virus/ recommendations/2016_17_north/en/

14. Castilla J, Navascués A, Casado I, Díaz-González J, PérezGarcía A, Fernandino L, et al. Combined effectiveness of prior and current season influenza vaccination in northern Spain: 2016/17 mid-season analysis. Euro Surveill. 2017;22(7):30465 https://doi.org/10.2807/1560-7917.ES.2017.22.7.30465 PMID: 28230523

15. Flannery B, Chung JR, Thaker SN, Monto AS, Martin ET, Belongia EA, et al. Interim Estimates of 2016-17 Seasonal Influenza Vaccine Effectiveness - United States, February 2017. MMWR Morb Mortal Wkly Rep. 2017;66(6):167-71. https://doi. org/10.15585/mmwr.mm6606a3 PMID: 28207689

16. Kissling E, Rondy MI-MOVE/I-MOVE+ study team. Early 2016/17 vaccine effectiveness estimates against influenza $\mathrm{A}\left(\mathrm{H}_{3} \mathrm{~N}_{2}\right)$ : I-MOVE multicentre case control studies at primary care and hospital levels in Europe. Euro Surveill. 2017;22(7):30464. https://doi.org/10.2807/1560-7917.ES.2017.22.7.30464 PMID: 28230524

17. Skowronski DM, Chambers C, Sabaiduc S, Dickinson JA, Winter AL, De Serres G, et al. Interim estimates of 2016/17 vaccine effectiveness against influenza $\mathrm{A}\left(\mathrm{H}_{3} \mathrm{~N}_{2}\right)$, Canada, January 2017. Euro Surveill. 2017;22(6):30460. . Available from: https:// doi.org/10.2807/1560-7917.ES.2017.22.6.30460 https://doi. org/10.2807/1560-7917.ES.2017.22.6.30460 PMID: 28205503

18. Smith DJ, Forrest S, Ackley DH, Perelson AS. Variable efficacy of repeated annual influenza vaccination. Proc Natl Acad Sci USA. 1999;96(24):14001-6. https://doi.org/10.1073/ pnas.96.24.14001 PMID: 10570188

19. Leung VK, Cowling BJ, Feng S, Sullivan SG. Concordance of interim and final estimates of influenza vaccine effectiveness: a systematic review. Euro Surveill. 2016;21(16):30202. https:// doi.org/10.2807/1560-7917.ES.2016.21.16.30202 PMID: 27124573

20. Sullivan SG, Kelly H. Late season interim estimates of influenza vaccine effectiveness reliably predict end of season estimates in Victoria, Australia, 2007 to 2012. Euro Surveill. 2013;18(41):20605. https://doi.org/10.2807/1560-7917. ES2013.18.41.20605 PMID: 24135124

21. Pan American Health Organization (PAHO). Weekly Influenza Report EW 39. Washington: PAHO; 11 Oct 2017. Available from: http://www.paho.org/hq/index.php?option =com docman\&task=doc_view\&Itemid $=270 \&$ gid $=42470 \& l a n g=$ en

22. World Health Organization (WHO). A manual for estimating disease burden associated with seasonal influenza. Geneva: WHO; 2015. Available from: http://www.who.int/influenza/ resources/publications/manual_burden_of_disease/en/

\section{License and copyright}

This is an open-access article distributed under the terms of the Creative Commons Attribution (CC BY 4.0) Licence. You may share and adapt the material, but must give appropriate credit to the source, provide a link to the licence, and indicate if changes were made.

This article is copyright of the authors, 2017. 